\title{
Modeling the effect of days and road type on peak period travels using structural equation modeling and big data from radio frequency identification for private cars and taxis
}

\author{
Tina Dzigbordi Wemegah ${ }^{1,2^{*}}$, Shunying Zhu ${ }^{1}$ and Charles Atombo ${ }^{3}$
}

\begin{abstract}
Purpose: The main congestion on roads occur during peak hours, apart from incidents such as road accidents and construction works. Although there have been studies on peak period travels, these studies have only implicitly considered weekday, weekend and road type in their investigations. In this paper, it is proposed to investigate explicitly, the effect of weekday and weekend travel variability and road type on peak hour vehicular movement which leads to congestion. A study of vehicular movement patterns during these times can influence and impact on planning decisions for transportation engineers.
\end{abstract}

Methods: This study utilizes structural equation model (SEM) to investigate the vehicular movements influence of weekdays, weekends, road type choice and car type on two peak hour periods $6 \mathrm{am}$ to $9 \mathrm{am}$ and $4 \mathrm{pm}$ to $7 \mathrm{pm}$ and one off-peak hour 9 am to 12 noon.

Results: Using vehicular movement data from Radio Frequency Identification for Nanjing, China, for the month of May 2014, it was revealed that in most of the cases, weekday travels influence peak hour travels more than weekends and that off-peak hour travels for both weekdays and weekends show little variations. The study also discovered that choice of road type and car type, have varying influence on peak hour travels.

Conclusions: The high significance ratios of results prove that these chosen variables are suitable for investigations into peak hour travel pattern studies. The study has also proved the viability of this modeling method to investigate policy measures to reduce peak period congestion.

Keywords: Structural equation model, Peak and off-peak period travel, Radio frequency identification, Travel patterns

\section{Introduction}

Travel patterns have changed over the years due to industrialization, car ownership increment, urbanization and many other factors, leading to an increase in road traffic congestion in urban areas. According to [1] congestion on the passenger road transport system is expected to increase by $36 \%$ by 2020 and conventional strategies like

\footnotetext{
* Correspondence: twemeg@yahoo.co.uk

${ }^{1}$ School of Transportation, Department of Traffic Engineering, Wuhan University of Technology, 1040 Heping Avenue, Wuhan 430063, Hubei, China ${ }^{2}$ Department of Civil Engineering, Accra Technical University, P.O. Box 561, Accra, Ghana

Full list of author information is available at the end of the article
}

the expansion of transport infrastructure cannot meet the demand of use of this infrastructure and thus transportation planning authorities are shifting from infrastructure expansion to more intelligent methods of transportation systems and demand management [2-4]. State-of-the-art methodology is therefore needed to cater for this problem and the use of RFID technology has been mentioned as one of the new approaches recommended to collect data to investigate traffic conditions [5]. With the insurgent of big data and corresponding applications, this study is therefore apt and opportune since it uses RFID technology and big data which is in a dynamic stage. 
Peak hour congestion on roads is one of the main concerns for traffic engineers as congestion during peak hours is the main cause of congestion on roads [6], apart from incidents such as road accidents, failure of traffic signals and construction works. A lot of policies have been put in place employing cutting-edge technology traffic management tools to reduce traffic congestion during peak hours [7]. Consistency and prior knowledge of travel inconsistency leading to a more reliable transport system are said to be more important to travelers than other factors like reduction in travel time [8]. A prior knowledge of peak hour patterns is therefore useful for the traveler. A study of vehicular movement patterns during times which are highly variable like peak periods can influence and have impact on planning decisions for transportation engineers.

Extensive studies have been carried out on the effects of time of day, on traffic volumes and disparities in traffic volumes over the hours of the day have long been noticed [9]. Downs Law on peak-hour traffic congestion states that peak-hour traffic congestion rises to meet maximum capacity on city highways [10], thus emphasizing the impact of peak hour movement on traffic congestion. This impact has induced various mitigating measures to reduce traffic congestion during peak hours including construction to increase the capacity of the roadway, transportation management systems like carpooling motivations, improving and provision of more reliable public transportation and promoting varying working hours to reduce the number of people traveling during peak hours and increasing fees for parking in the center districts $[11,12]$. Although these measures have been put in place, we still experience traffic congestion $[11,13]$ during peak hours.

Study of peak time and off-peak time travel analysis and impact in the transportation discipline has spanned many methods and goals over several decades. Loudon et al. [9] used a regression model to prove the need for peak period travel studies for planning new and providing better transportation facilities. They applied their study to different facilities but did not investigate the effect of days on the peak period spread. Ben-Akiva et al. [12] also used a dynamic markovian model to perform simulation experiments for peak hours in an effort to propose measures to reduce peak period congestion. They, however, did not investigate the variables contributing to the peak period congestion. Yan et al. [7] constructed a complex network using a weighted Frobenius to determine likeliness between multivariate time series and principal component analysis for weights and further exploited normalized network structure entropy and the cumulative probability of degree to postulate a similarity in pattern between these statistical properties for morning and evening peak period traffic flow parameters. Their study even though looked at traffic flow within hours of the day, did not also tackle the contributing factors, just like the previous study. Lyons et al. [13] focused their study on investigating the impact of restriction of movement of trucks during peak hours on congestion in Mexico, employing statistical and traffic assignment analysis using various scenarios. They concluded that the restriction rather had a negative impact on congestion. Their study, therefore, identified the inconsequential effect of the heavy track restriction without investigating the influence of other factors.

Studies in Europe have used different technologies and methods to address traffic flow pattern. Some of these studies used neural networks [14, 15] and Floating Car Data (FCD) System [15-17]. For instance, Anuar et al. [17] conducted a study in Spain and used Floating Car Data (FCD) and loop detectors to develop the relationship between flow and speed. In another study conducted in Turkey, Altintasi et al. [16] used a search algorithm to identify traffic congestion patterns along urban roads using data collected from FCD for morning peak hours for two months. Their study concentrated on only morning peak and on only urban roads and not on other roads or evening peak hours. Berk Celikoglu [18],Celikoglu [14] also acquired traffic data from the Remote Traffic Microwave Sensor Data (RTMS) and proposed Level of Service based classification for the derivation of a traffic flow fundamental diagram. Altintasi et al. [16] also used a search algorithm to identify traffic congestion patterns along urban roads using data collected from floating car for morning peak hours for two months. Their study concentrated on only morning peak and on only urban roads and not on other roads or evening peak hours.

These researchers in Europe and other parts of the world although have breached part of the gap of research on peak and off-peak hour travels, they have done so implicitly. In this paper, it is proposed as being useful to investigate explicitly, the effect of weekday and weekend travel pattern variability on peak hour vehicular movement which leads to congestion. Other previous studies have only considered these variables implicitly We address the gaps addressed in the previous paragraph in this paper as we investigate the influence of weekday, weekend and road type choice on the peak hour vehicular movement of private cars and taxis. These two categories of vehicles were chosen since they make up over $90 \%$ of vehicles in Nanjing. Cheng et al. [19] stated that there are about 1.2 million cars in Nanjing and out of which SAP [20] indicates that there are about one million private cars, ten thousand taxicabs, and seven thousand buses running in the city. 
Another study conducted in Italy used FCD and proposed a neural network-based model to estimate average speed and determine congestion locations [15]. The current research observes the variability of the attributes involved mainly between temporal variables of weekday, weekends, peak hours, off-peak hours and other variables like road type and type of vehicle (taxi and private) and found structural equation model (SEM) a suitable choice. This is because SEM can handle many variables and is also effective in analyzing how these variables affect each other [21-23]. The second reason for using SEM is that it has been known to be well suited for large data sets [24, 25] and this research has data of over 120 million records of vehicular movement involving over 830,000 vehicles. Data for the structural equation model is from Radio Frequency Identification (RFID) of Nanjing for the month of May 2014. SEM was developed to identify the influence of weekday and weekend vehicular movement as well as road type choice on peak hour travels for taxis and private cars.

The overall purpose of this study is to identify how these variables contribute to peak hour traffic and thus determine travel patterns during these peak hours. This will, in turn, inform transport authorities to manage road network operations to ease congestion during peak periods.

The rest of the paper is organized as follows: Section 2 presents relevant literature pertaining to this study including the reason for the choice of variables which is in subsection 2.1. Section 3 presents the hypothesis on which the research is based. Section 4 presents the materials and methods of the study, detailing the study area, the data, and variables used as well as the measurement model. Section 5 presents the results and analysis of the model under each of the four hypothesis of the study. Section 6 presents the conclusion, explaining some practical implications of the study and puts forward some suggestions for future study.

\section{Relevant literature}

A structural equation model (SEM) is a statistical method that allows for testing of hypothesis between variables either latent or observed [26, 27]. SEM draws its advantage from the fact that it allows analysis of the relationship between latent and observed variables [28] and does not limit the number of dependent variables in a model to only one, unlike other regression models. Latent variables, also called factors are variables that are not measured directly but measured through a set of observed variables. Observed variables as its name denotes are measured variables from data sources like questionnaires and measurement tools like GPS, RFID, inductive loop detectors, etc.
The SEM follows a procedure for which every SEM should essentially follow and Kline [24] clearly outlines them as follows: a) Specification of the model. This involves specifying the hypothesis in the model to be created and looking at the relationship between variables. b) Identification of model, which is concerned with identifying theoretically based parameters that ensure that it is possible to develop an estimate of every model parameter. c) Collection and scrutinizing of data collected to make sure it is appropriate. d) The model is estimated by evaluating how well the model describes the data, if parameters are significant enough for model fit and inferring the parameter estimates to make sure the model chosen is the most suitable compared to others. e) The fifth step involves confirmation of the suitability of the model chosen and if unsuitable then the model is re-specified. The final step is the presentation of the SEM analysis comprehensively.

SEM has been used in varied applications in transportation studies ranging from traffic pattern studies, travel mode choice to travel behavior patterns. Kurle et al. [29] did a study on the way five different types of vehicles use lanes, employing factors of vehicle composition, traffic flow, and speed. Their study utilized data collected for only an $8 \mathrm{~h}$ period including both peak and off-peak hours, using SEM to develop four equations for four lanes. Qin et al. [30] also utilized SEM for analyzing the relationship between compelling factors and choice of travel modes like walking, riding on bus, car or railway. Van Acker, Witlox [23] investigated car ownership as a mediating factor between the built environment and usage of the car using SEM and confirmed the dual usage of car ownership as both a dependent and an independent variable. Li et al. [11] conducted a research on residential areas to investigate the factors influencing mode choice of short distance travels using SEM. Jin Kim et al. [31] used SEM to conduct a study to determine travel patterns of travelers in preparation of a policy change from a 6-day work week to a 5-day work week that was being used.

There have been few studies that have utilized SEM for peak and off-peak hour studies and these studies have not used variables to predict peak and off-peak hours but rather used peak hour travels to predict other variables. For instance, Eboli, Mazzulla [32] used SEM for evaluating passengers perception about railway services. The use of peak and off-peak hours in this study was only used for data collection purposes to have a data that encompasses all the variations of hours in a day. Smith [33] in his dissertation, used SEM to test the two hypothesis that, peak hours travel will be related to lower travel well-being whiles off-peak travel time will be related to better travel well-being and secondly travel well-being will vary by distance, congestion, peak- hour 
travel and other trip factors. These studies combine peak and off-peak hour variables to study its effect on other variables.

This study differs from the above mentioned related studies in the sense that it uses other variables (road type, weekday and weekend vehicle movement) to investigate the effects on peak hour travels when the previous studies, have instead investigated the effect of peak period travels on the variables. In addition, the study uses big data from RFID technology which is a fast-growing technology used in many transportation applications but has been less researched on [34] in the area movement analysis. The AMOS 22.0.0 software suite was used to do the confirmatory factor analysis and SEM.

\subsection{Reasons for choice of variables}

This study employed weekday, weekend, road type, type of car that is taxi or private car variables to explain their effect on peak hour travels. In this section, we explain the similarities of variable choice with others studies and state how our study is different from other studies. Van Wee et al. [35] stated in their study the importance of temporal factors on travel behavior, emphasizing that there are opportunities available depending on the time of day chosen. This goes to explain the relevance of weekday, weekend and time of day factors in analyzing travel patterns. Yu et al. [36] used weekday peak hour, weekday non-peak hour and weekend non-peak hour to investigate different crash rate circumstances. Even though this was used to investigate crash rates, whereas our study uses it for vehicular movement, it still serves as valuable variables for peak hour traffic studies. Loudon et al. [37] argued in their research the need to specifically model peak hour travels instead of the traditional way of making assumptions with percentages based on twenty-four-hour estimates. They used 6 am to 9 am peak period and $3 \mathrm{pm}$ to $6 \mathrm{pm}$ off-peak period travel for their research. Our research descriptive statistics, however, confirmed the 6 am to 9 am morning peak period but had a $4 \mathrm{pm}$ to $7 \mathrm{pm}$ evening peak period instead. Chen et al. [38] also employed peak and off-peak hour variables to investigate the influence of congestion and passenger load on bus emissions compared with passenger cars but they only collected data for weekdays. Chiou, Fu [39],Seedam et al. [6] only used 7 am to 9 am morning peak period variable in their study but the former used it to study behaviors of drivers with respect to congestion charges while the latter used it to investigate motorcycles impact on fuel consumption and emissions. Holguin-Veras et al. [40] in their study to report the results of a project that evaluated the effects of a pricing initiative on the behavior of passengers, used variables of weekday and weekend peak and off-peak period travels, and also employed a morning peak period of 6 am to 9 am and evening peak period of $4 \mathrm{pm}$ to $7 \mathrm{pm}$. Their study was however focused on passenger behavioral changes. Ben-Elia, Ettema [41], also used peak periods in their research but used it to investigate a reward system for not commuting during peak hours of $6.30 \mathrm{am}$ to $9.30 \mathrm{am}$. Yazici et al. [42] analyzed temporal travel variances between urban roads and highways and concluded that there is a variability of travel time patterns between urban roads and highways. They also used different vehicles for their analysis but did not specifically conclude on the relationship between these vehicle types and peak or off-peak hour travels. These previous studies have used only one or two road types in their investigations whereas our paper employs the choice of four (4) road types (secondary, primary, tertiary and motorway). Tarko, Perez-Cartagena [43] utilized temporal and spatial variables for their investigation on peak hour factor but used site to site analysis instead of the type of road we are using for the analysis. They concluded on the significance of spatial factor on peak hour factor variability, thus further endorsing the importance of our choice for road type as a variable for peak hour investigations.

\section{Research hypothesis}

There are in all four considered conceptual model hypotheses $\mathrm{H} 1, \mathrm{H} 2, \mathrm{H} 3$, and $\mathrm{H} 4$. The initial hypothesis was made up of three hypotheses, $\mathrm{H} 1, \mathrm{H} 2$ and $\mathrm{H} 3$. However, a fourth hypothesis ( $\mathrm{H} 4)$ was further formulated because the research data set include taxis and private cars and it is important to consider how each of the two car type movements influences peak and off-peak hours taking into consideration days and road choice.

H1: The movement of the cars during weekdays will significantly influence the movement during peak and off-peak period travels.

$\mathrm{H} 2$ : The movement of the cars during weekends will significantly influence the movement in peak and offpeak period travels.

H3: The choice of road type by cars (taxis and private cars) will significantly influence the movement during peak and off-peak period.

H4: Private cars will have a more significant influence on peak and off-peak period travels and their choice of road type will have more significance in predicting peak and off-peak hour travels than taxis.

\section{Materials and methods}

\subsection{Study area}

Nanjing which used to be the capital of China but now the capital of the Jiangsu Province has inherent urban traffic issues of peak time traffic congestion. The Nanjing RFID 
project which started in 2010 was originally intended to meet the needs of testing vehicle emission standards, provide smart parking management, conduct urban traffic management and analyze and offer traffic monitoring services. Each vehicle registered in Nanjing was installed with an RFID electronic tag and RFID readers were installed with video capturing devices along designated streets in the town. The data recorded by the readers of the vehicles is transmitted to the Nanjing Information Center. By 2015 Nanjing had over 518 base station readers and electronic tags on vehicles.

\subsection{Data}

The RFID data for this research covers the month of May in 2014. The RFID vehicle movement data covers over 881,103 vehicles with a record of over $122,000,000$ delivered as a text file. The initial data consist of three datasets: The vehicle path data, the vehicle type data, and the RFID reader data. The vehicle path data is made up of the license number of the vehicles (Lic_No), the date and time the vehicle was spotted by the RFID reader, the vehicle type code, the number of lanes of the road and the RFID reader ID. The vehicle type data is made up of the vehicle type code and the vehicle type. The RFID reader data is made up of the RFID reader ID, the road name that the RFID reader has been installed, the longitude and latitude of the RFID reader and the number of road lanes on which the RFID reader is installed. Samples of the three datasets and their attributes are shown in Tables 1,2 and 3. The license numbers of vehicles for this paper are scrambled to protect the identity of the vehicle owners. This study utilizes RFID readers covering 496 base stations installed in Nanjing city and used to capture the data.

\subsection{Variables}

There are five groups of variables namely weekdays, weekends, road type, vehicle type and peak and off-peak hours that was extracted from the raw data and used for the study. The weekdays have 5 variables (Mondays, Tuesdays, Wednesdays, Thursdays, Fridays) while the

Table 1 Vehicle path data

\begin{tabular}{llllll}
\hline Lic_No & Date & $\begin{array}{l}\text { Time } \\
\text { (hr:min:sec) }\end{array}$ & $\begin{array}{l}\text { Vehicle } \\
\text { type code }\end{array}$ & Lanes & RFID reader ID \\
\hline AV4688 & $5 / 1 / 2014$ & $12: 37: 04$ & 101 & 2 & 6242 \\
YW4578 & $5 / 1 / 2014$ & $12: 38: 12$ & 103 & 1 & 6344 \\
AM8923 & $5 / 3 / 2014$ & $12: 40: 27$ & 200 & 2 & 6345 \\
VC2584 & $5 / 5 / 2014$ & $12: 42: 04$ & 303 & 2 & 6346 \\
JB3254 & $5 / 15 / 2014$ & $12: 43: 35$ & 311 & 1 & 6347 \\
DW3694 & $5 / 30 / 2014$ & $12: 46: 07$ & 312 & 2 & 6335 \\
DW6214 & $5 / 24 / 2014$ & $12: 50: 41$ & 900 & 3 & 6144 \\
\hline
\end{tabular}

Table 2 Vehicle type data

\begin{tabular}{ll}
\hline Vehicle type code & Vehicle type \\
\hline 101 & Large Bus \\
103 & Small bus \\
200 & Truck \\
303 & Trailer \\
311 & Coach Car \\
312 & Police Car \\
900 & Other \\
\hline
\end{tabular}

weekend has 2 variables (Saturdays and Sundays). The vehicle types used for the study are private cars and taxis. The road types consist of four classes: motorway, primary, secondary and tertiary roads. The road classification was adapted from OpenStreetMap (OSM). The OSM data for Nanjing city was downloaded using BBBike online service (extract.bbbike.org). The downloaded data was further converted to ESRI ArcGIS Network data set using the ArcGIS OSM Editor Toolbox. The road types used are a modified version of classification of roads by OSM, where living street and trunk roads are omitted. Readers falling on living street and trunk roads were assigned road types in our classification closest to roads connecting these road types. The RFID readers are installed along roads, thus assigning a road type to each RFID reader. A vehicle tracked by an RFID reader therefore also automatically determines the classification of road that vehicle is using. The peak and off-peak period variables group consist of three variables: morning and evening peak-periods from 6 am to 9 am and between $4 \mathrm{pm}$ to $7 \mathrm{pm}$ respectively and off-peak hours from 9 am to 12 noon.

The vehicle type codes columns in Tables 1 and Table 2 make it possible for each vehicle type in Table 2 to be known. The RFID_ID columns in Tables 1 and 3 also serve as a primary key allowing Tables 1 and 3 to be joined, thus combining vehicle path data to the RFID reader data. Joining Tables 1 and 3 is beneficial for retrieving vehicles' locations at specific dates and times and thus determining the movement of the vehicles. For example, in Table 4, for vehicle with Lic_No. AV4688, the path of the vehicle from the time 12.37 to $12.50 \mathrm{can}$ be traced and the number of times the vehicle was detected by RFID readers can be determined within this time period.

\subsection{Data processing and descriptive statistics}

The study focused on private cars and taxis both of which have the vehicle type code 103 and are designated as small buses as shown in Table 2. Pre-processing and initial viewing of the data was done using PostgreSQL 9.4 software. The data was next exported to SPSS for 
Table 3 RFID reader data

\begin{tabular}{llll}
\hline RFID reader ID & RFID road name & Longitude & Latitude \\
\hline 6228 & Central Road South of Heilongjiang Road West & 118.7840010 & 32.0865790 \\
6233 & Fu Hougang Central Road, East of the South & 118.7842490 & 32.0644510 \\
6235 & North of Zhujiang road, Zhongshan Road East & 118.7843410 & 32.0508940 \\
6236 & Zhujiang Road, Zhongshan Road South West & 118.7839970 & 32.0476220 \\
6238 & South of the Chang Jiang Road, Zhongshan Road West & 118.7840160 & 32.0441820 \\
6240 & Improved road, jianye road, South West & 118.7777640 & 32.0306670 \\
6242 & Zhongshan South Road, baixia Road South West & 118.7838580 & 32.0294210 \\
\hline
\end{tabular}

further processing. The descriptive statistics revealed that private cars and taxis make up over $90 \%$ of vehicles in Nanjing. The rest of the vehicle types were therefore filtered out and deleted leaving only private cars and taxis, amounting to a total record of $111,147,589$ made up of 830,193 vehicles. The distribution of the total number of records, which represents the number of times the RFID reader detected vehicles for each day of the week is shown in Table 5. To differentiate between which vehicles are taxis and which are private cars, the number of times the RFID reader detected a vehicle and the total counts for that particular vehicle was used. The number of times a vehicle was counted by RFID readers in a day was tried out until an optimal number of counts per day were assigned to private cars and taxis. Counts greater than 25 per day were taken to be taxis and counts lower than 25 per day were considered as private cars. This procedure gave the total number of taxis as 10,228 and private cars as 819,965 which corroborated with the Nanjing statistical yearbook of 2014 and SAP [20].

The variable values were determined using the number of times each vehicle is detected by the RFID reader. The number of detections for each vehicle for Mondays through to Sundays was determined using SPSS for the month of May 2014. Similarly, the total number of detections for peak hours 6 am to 9 am and $4 \mathrm{pm}$ to $7 \mathrm{pm}$ and off-peak hours of 9 am to 12 noon were also determined. Each vehicle is detected on a particular road by the RFID reader with the reader ID used as a reference.
Knowing the longitudes and latitudes for each of the RFID readers, the positions of the readers were plotted in a GIS software. The OSM data was draped on the plotted RFID positions after which each reader was labeled with a road type. The roads were inspected with respect to each RFID reader and each reader assigned to the road on which it coincided or with the road closest to it. Thus, each vehicle movement was assigned as motorway, secondary, primary or tertiary roads as shown in Table 4. The total number of times each vehicle used a road type was computed. Peak and off-peak-hour times were chosen based on previous literature as explained earlier in the variables section and also revealed from the one month histogram of May 2014 as shown in Fig. 1. These peak and off-peak periods were also chosen because various literature and investigations used similar peak hours [37, 40, 41]. The rest of the hours displayed similar characteristics as the hours chosen and presumed therefore that they will exhibit same results as hours chosen for study. A sample of values computed and used for the model is displayed in Table 6 .

\subsection{Measurement model}

Based on previous study recommendations, a two-step approach was used for the analyses [44, 45]. Before testing of the structural model, the indicators were subjected to Confirmatory Factor Analysis (CFA) to evaluate how each item represents their corresponding latent variables and also determine the validity and reliability of the scale. Because the construct of weekday and weekend were

Table 4 Combined vehicle path and RFID reader ID table

\begin{tabular}{lllllllll}
\hline Lic_No. & Date (month/day/year) & Time (hr:min:sec) & Vehicle type code & Lanes & RFID reader ID & Longitude & Latitude & Road type \\
\hline AV4688 & $5 / 1 / 2014$ & $12: 37: 04$ & 103 & 2 & 6242 & 118.78385800 & 32.02942100 & Tertiary \\
AV4688 & $5 / 1 / 2014$ & $12: 38: 12$ & 103 & 1 & 6344 & 118.78306400 & 32.02349500 & Primary \\
AV4688 & $5 / 1 / 2014$ & $12: 40: 27$ & 103 & 2 & 6345 & 118.78569800 & 32.02290400 & Primary \\
AV4688 & $5 / 1 / 2014$ & $12: 42: 04$ & 103 & 2 & 6346 & 118.79171100 & 32.02361400 & Secondary \\
AV4688 & $5 / 1 / 2014$ & $12: 43: 35$ & 103 & 1 & 6347 & 118.79535900 & 32.02382300 & Tertiary \\
AV4688 & $5 / 1 / 2014$ & $12: 46: 07$ & 103 & 2 & 6335 & 118.80226300 & 32.02627000 & Tertiary \\
AV4688 & $5 / 1 / 2014$ & $12: 50: 41$ & 103 & 3 & 6144 & 118.81718090 & 32.01982343 & Secondary \\
\hline
\end{tabular}


Table 5 Distribution of records for each day of week

\begin{tabular}{ll}
\hline Day of week & Number of records \\
\hline Sunday & $13,934,974$ \\
Monday & $14,886,439$ \\
Tuesday & $15,081,782$ \\
Wednesday & $15,124,193$ \\
Thursday & $18,576,566$ \\
Friday & $19,146,741$ \\
Saturday & $14,396,894$ \\
Total & $111,147,589$ \\
\hline
\end{tabular}

common, the second order CFA was employed. In all, 57 parameters were estimated consisting of 32 regression weights, 6 covariances, and 19 variances.

According to previous studies, goodness-of-fit index (GFI), adjusted goodness-of-fit index (AGFI), comparative fit index (CFI) and normed fit index (NFI) values of 0.9 or above and root mean square error of approximation (RMSEA) of 0.08 or less indicate a good fit between the model and the data $[45,46]$. As displayed in Fig. 2, the model fitted the observed variance-covariance matrix very well and was within the acceptable range as the comparisons fit indices were all above 0.09 and RMSEA of less than 0.08 was achieved. The standardized regression weights of the observed variables range from 0.65 to 0.89 with a significant level of $p<0.001$, indicating that, the observed variables significantly represent their respective latent constructs and permitted for further analysis. The squared multiple correlations (SMCs) range from 0.42 to 0.79 indicating the explanatory power of the research model.

\subsection{Discriminant and convergent validity}

In Table 7, the result shows that all the composite reliabilities (CRs) were over the recommended value of 0.7 , [46], indicating that the scales were reliable. The average variance extracted (AVE) for each construct ranged from 0.68 to 0.77 and the square roots of AVE of each construct were greater than the correlation coefficients with other constructs, suggesting that the scales have good convergent and discriminant validity.

\section{Results and discussion}

\subsection{Weekdays and weekend predicting peak hours}

From Fig. 3, it is clear that the independent variables (weekdays) positively predicted dependent variables (the peak and off-peak hours) from 6 am to 9 am, 9 am to 12 noon and $4 \mathrm{pm}$ to $7 \mathrm{pm}$. On Mondays, the movement of the vehicles for morning peak hours, from 6 am to 9 am $(\beta=0.20$, t-value $=97.29, p<0.001)$ and evening peak hours from $4 \mathrm{pm}$ to $7 \mathrm{pm}(\beta=0.21, \mathrm{t}$-value $=135.35$, $p<0.001)$ are more than off-peak hours from 9 am to 12 noon $(\beta=0.13$, $\mathrm{t}$-value $=88.95, p<0.001)$. Concerning the movement of vehicles on Tuesdays, evening peak hours, $4 \mathrm{pm}$ to $7 \mathrm{pm}$ was higher followed by off-peak hours, 9 am to 12 noon with morning peak, 6 am to 9 am showing the least vehicle movement. The result further show that on Wednesdays the movement of the vehicles for morning peak, 6 am to 9 am and off-peak hours 9 am to 12 noon were greater

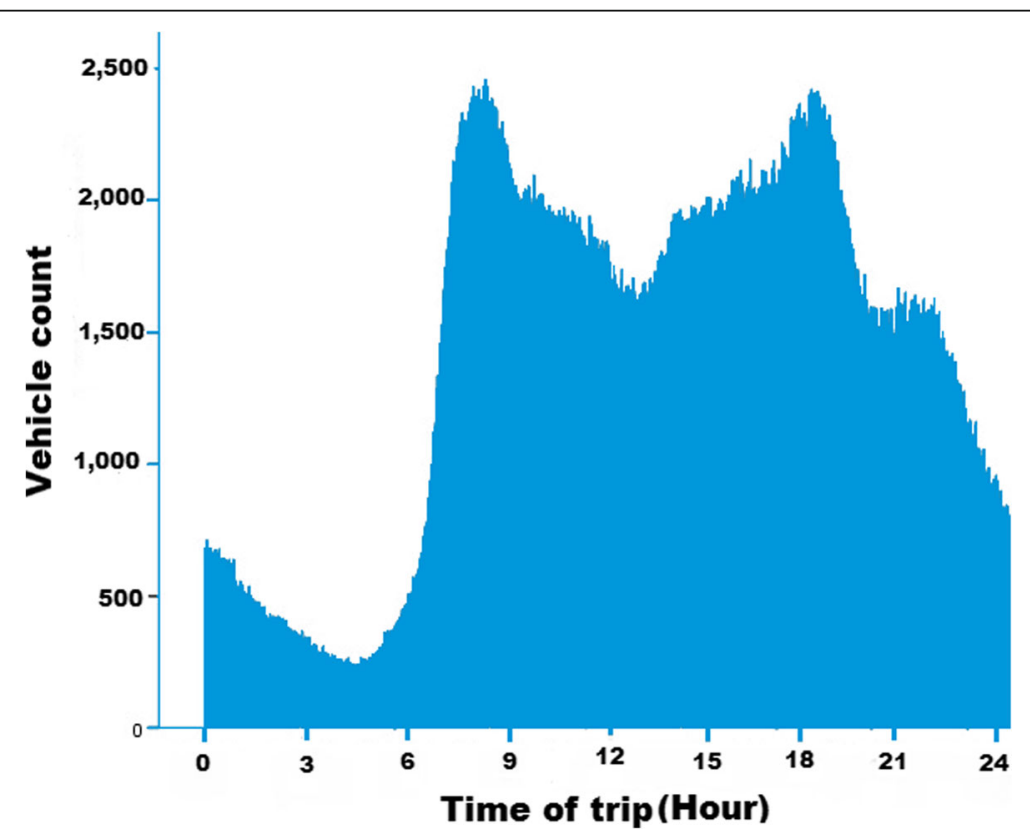

Fig. 1 Histogram of 24-h vehicle counts for May 2014 
Table 6 A sample of variables used with their corresponding values

\begin{tabular}{lllllllllllllll}
\hline Lic_No & Mon & Tues & Wed & Thurs & Fri & Sat & Sun & 6 am-9 am & 9 am-12 noon & 4 pm-7 pm & Motorway & Primary & Secondary & Tertiary \\
\hline 7290A3 & 46 & 24 & 21 & 16 & 33 & 8 & 12 & 9 & 60 & 15 & 2 & 39 & 4 & 65 \\
56880A & 7 & 13 & 15 & 29 & 13 & 15 & 5 & 0 & 50 & 24 & 0 & 17 & 13 & 46 \\
A20000 & 4 & 8 & 1 & 8 & 4 & 8 & 2 & 0 & 4 & 10 & 1 & 0 & 4 & 28 \\
A50000 & 40 & 35 & 15 & 29 & 18 & 9 & 5 & 30 & 36 & 36 & 1 & 14 & 60 & 49 \\
A80000 & 0 & 0 & 0 & 4 & 6 & 0 & 0 & 0 & 3 & 0 & 0 & 1 & 0 & 9 \\
A90000 & 22 & 26 & 8 & 23 & 28 & 8 & 1 & 33 & 53 & 12 & 4 & 21 & 17 & 29 \\
AC0000 & 0 & 2 & 1 & 2 & 3 & 0 & 0 & 0 & 1 & 3 & 0 & 1 & 1 & 4 \\
AE0000 & 32 & 23 & 17 & 22 & 54 & 30 & 31 & 36 & 37 & 45 & 7 & 67 & 61 & 54 \\
AL0000 & 7 & 17 & 9 & 2 & 3 & 1 & 3 & 0 & 9 & 1 & 0 & 10 & 11 & 8 \\
AM0000 & 60 & 74 & 54 & 40 & 83 & 31 & 52 & 72 & 33 & 71 & 11 & 72 & 139 & 102 \\
AT0000 & 1 & 21 & 3 & 8 & 4 & 11 & 21 & 4 & 17 & 11 & 3 & 10 & 20 & 24 \\
\hline
\end{tabular}

$(\beta=0.16, \mathrm{t}$-value $=79.82, p<0.001 ; \beta=0.15, \mathrm{t}$-value $=$ 98.06, $p<0.001$ respectively) than evening peak hours $4 \mathrm{pm}$ to $7 \mathrm{pm}$. On Thursdays, the movement of the vehicles for off-peak hours 9 am to 12 noon $(\beta=0.18$, $\mathrm{t}$-value $=105.67, p<0.001)$ is more, followed by morning peak hours, 6 am to 9 am $(\beta=0.16$, t-value $=70.68$, $p<0.001)$. The least movements among the Thursdays are the evening peak, $4 \mathrm{pm}$ to $7 \mathrm{pm}$. On Fridays, the movement of vehicles in the morning peak, from 6 am to 9 am $(\beta=0.21, \mathrm{t}$-value $=93.78, p<0.001)$ and the evening peak hour, from $4 \mathrm{pm}$ to $7 \mathrm{pm}(\beta=0.24$, $\mathrm{t}$-value $=137.60, p<0.001)$ are higher than off-peak hours 9 am to 12 noon. The Friday evening peak hours are however slightly higher than morning peak hours as also corroborated by findings from Viti et al. [47],Yazici et al. [42]. Generally, weekday movement has a significant influence on peak hours. However, from the result, it is obvious that the coefficient weight

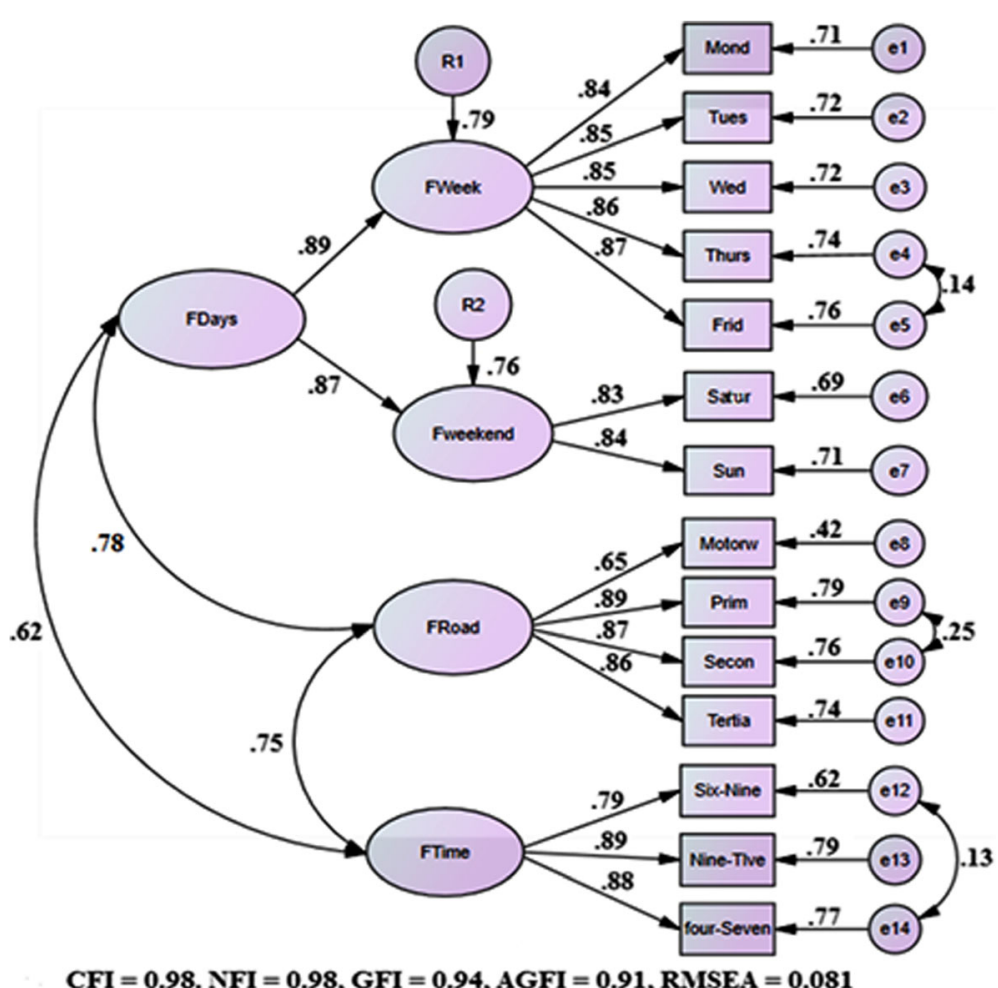

Fig. 2 Measurement model. *Note: Monday - Mond, Tuesday -Tues, Wednesday - Wed, Thursday - Thurs, Friday - Frid, Saturday - Satur, Sunday - Sun, Motorway - Motorw, Primary roads - Prim, Secondary roads - Secon, Tertiary roads - Tertia, 6 am to 9 am - Six-Nine, 9 am to 12 noon - Nine-Tlve, 4 pm to $7 \mathrm{pm}$ - four-Seven 
Table 7 Discriminant and Convergent Validity (Square root of AVE on the diagonal cells)

\begin{tabular}{|c|c|c|c|c|c|}
\hline Factors & Composite reliability & AVE & Road type & Days & Peak/off-peak hours \\
\hline Road Types & 0.894 & 0.682 & 0.826 & & \\
\hline Days & 0.873 & 0.775 & 0.780 & 0.880 & \\
\hline Peak/Off-peak hours(time) & 0.890 & 0.729 & 0.750 & 0.620 & 0.854 \\
\hline
\end{tabular}

AVE Average variance extracted. All correlation coefficients were significant at $P<0.001$

of Mondays and Fridays appears to be greater compared to other weekdays.

On the other hand, again from Fig. 3, during weekends, except the path from Sundays morning's peak from 6 am to 9 am, which is not significant, all the paths coefficients were significant. Nevertheless, the weight of the significance was not strong, suggesting less possibility of traffic congestion occurring during weekends. The movement of the vehicles on weekends appears to be less on all the peak hours compared to the weekdays.

The result further shows that when the weekdays alone were included in the model, the model explained $63 \%, 80 \%$ and $78 \%$ of the variance at 6 am to 9 am, 9 am to 12 noon and $4 \mathrm{pm}$ to $7 \mathrm{pm}$ peak hours respectively. When the weekends were included in the model, $1 \%$ of the variance was added to the 9 am to 12-noon off-peak hour as shown in Fig. 3. Specifically, considering both the weekends and weekdays in the model, the total amount of the variance explained in the morning, noon off-peak and the evening peak hours were $63 \%, 81 \%$, and $78 \%$ respectively. This also further confirms that weekdays made more significant influence than weekends on peak hours.

From all these results, it essentially means that movements of vehicles during morning peak hours 6 am to 9 am are less dispersed but more significant connoting that morning peak hour movements have similar patterns as compared to evening off-peak from $4 \mathrm{pm}$ to $7 \mathrm{pm}$. The hours with least patterns are morning off-peak from 9 am to 12 noon, even though day of the week and time of the day have more significance on morning peaks than off-peak hours as also verified by [48]. This is understandable in that for morning peak hours most people are either moving to their workplace, school or regular activity for the day, whereas with off-peak hours, the movement is less predictable as no regular pattern is discerned. For weekends, it is reasonable that there will be more vehicular movement during off-peak hours since most people do not need to meet the morning hour rush time but can decide to travel after 9 am.

\subsection{Comparing the movement of private and taxis predicting peak hours}

In this research, which includes identifying the significance of car types contributing to peak hour traffic in Nanjing, it was important to compare the movement between taxis and private cars which forms the majority of cars in Nanjing. From Table 8, the result shows that on Mondays and Wednesdays, the movement of the private cars is more than the taxis on all the peak hours. On Tuesdays, the movement of the taxis in the morning

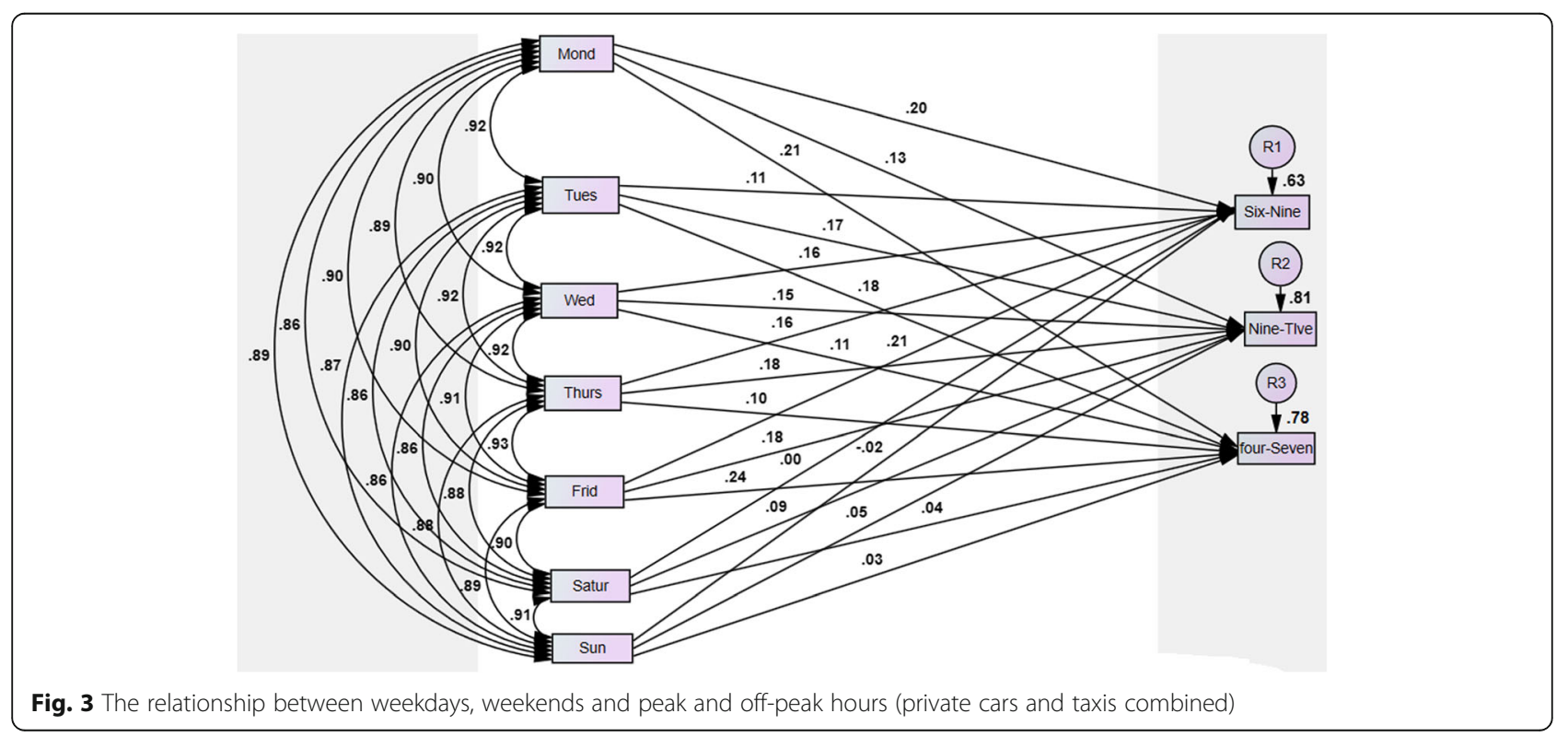


Table 8 Structural Model: Comparing the movement of private car and taxi predicting peak hours

\begin{tabular}{|c|c|c|c|c|c|c|}
\hline \multirow[t]{2}{*}{ Paths } & \multicolumn{3}{|c|}{ Private cars - Default Model N=819965 } & \multicolumn{3}{|c|}{ Taxi - Defaults Model $N=10228$} \\
\hline & Estimate & SE & Critical Ratio & Estimate & SE & Critical Ratio \\
\hline Monday $\rightarrow 6$ am-9 am & $0.17^{* * *}$ & 0.002 & 115.46 & $0.11^{* * *}$ & 0.02 & 7.67 \\
\hline Monday $\rightarrow 9$ am-12 noon & $0.15^{* * *}$ & 0.002 & 107.54 & $0.04^{*}$ & 0.01 & 2.84 \\
\hline Monday $\rightarrow 4$ pm-7 pm & $0.15^{* * *}$ & 0.002 & 133.54 & $0.15^{* * *}$ & 0.01 & 11.19 \\
\hline Tuesday $\rightarrow 6$ am-9 am & $0.15^{* * *}$ & 0.002 & 96.00 & $0.03^{\mathrm{ns}}$ & 0.02 & 1.67 \\
\hline Tuesday $\rightarrow 9$ am-12 noon & $0.14^{* * *}$ & 0.002 & 97.47 & $0.15^{* * *}$ & 0.01 & 11.03 \\
\hline Tuesday $\rightarrow 4$ pm-7 pm & $0.15^{* * *}$ & 0.002 & 126.68 & $0.14^{* * *}$ & 0.01 & 9.21 \\
\hline Wednesday $\rightarrow 6$ am-9 am & $0.15^{* * *}$ & 0.002 & 98.05 & $0.13^{* * *}$ & 0.01 & 9.30 \\
\hline Wednesday $\rightarrow 9$ am-12 noon & $0.14^{* * *}$ & 0.002 & 98.36 & $0.11^{* * *}$ & 0.01 & 9.13 \\
\hline Wednesday $\rightarrow 4$ pm-7 pm & $0.15^{* * *}$ & 0.002 & 132.78 & $0.03^{\mathrm{ns}}$ & 0.01 & 1.86 \\
\hline Thursday $\rightarrow 6$ am-9 am & $0.13^{* * *}$ & 0.002 & 81.26 & $0.21^{* * *}$ & 0.01 & 13.60 \\
\hline Thursday $\rightarrow 9$ am-12 noon & $0.15^{* * *}$ & 0.002 & 106.63 & $0.20^{* * *}$ & 0.01 & 14.21 \\
\hline Thursday $\rightarrow 4$ pm-7 pm & $0.14^{* * *}$ & 0.002 & 124.71 & $0.12^{* * *}$ & 0.01 & 7.91 \\
\hline Friday $\rightarrow 6$ am -9 am & $0.14^{* * *}$ & 0.002 & 95.66 & $0.14^{* * *}$ & 0.01 & 8.22 \\
\hline Friday $\rightarrow 9$ am-12 noon & $0.14^{* * *}$ & 0.002 & 102.59 & $0.14^{* * *}$ & 0.01 & 9.24 \\
\hline Friday $\rightarrow 4$ pm-7 pm & $0.18^{* * *}$ & 0.001 & 156.33 & $0.20^{* * *}$ & 0.01 & 12.14 \\
\hline Saturday $\rightarrow 6$ am -9 am & $0.03^{* *}$ & 0.002 & 28.33 & $0.11^{* * *}$ & 0.02 & 6.94 \\
\hline Saturday $\rightarrow 9$ am-12 noon & $0.10^{* * *}$ & 0.002 & 90.98 & $0.13^{* * *}$ & 0.01 & 9.21 \\
\hline Saturday $\rightarrow 4$ pm-7 pm & $0.10^{* * *}$ & 0.001 & 122.13 & $0.10^{* * *}$ & 0.01 & 6.91 \\
\hline Sunday $\rightarrow 6$ am -9 am & $0.03^{* *}$ & 0.002 & 21.99 & $0.06^{* * *}$ & 0.02 & 3.74 \\
\hline Sunday $\rightarrow 9$ am-12 noon & $0.07^{* * *}$ & 0.002 & 65.43 & $0.09^{* * *}$ & 0.01 & 6.41 \\
\hline Sunday $\rightarrow 4 \mathrm{pm}-7 \mathrm{pm}$ & $0.10^{* * *}$ & 0.002 & 113.37 & $0.06^{* * *}$ & 0.01 & 4.41 \\
\hline \multicolumn{4}{|l|}{$R^{2}: 6 a m-9 a m=50 \%$} & \multicolumn{3}{|c|}{$R^{2}: 6 a m-9 a m=48 \%$} \\
\hline \multicolumn{4}{|l|}{$R^{2}: 9$ am-12 noon $=58 \%$} & \multicolumn{3}{|c|}{$R^{2}: 9 \mathrm{am}-12$ noon $=58 \%$} \\
\hline \multicolumn{4}{|l|}{$R^{2}: 4 p m-7 p m=72 \%$} & \multicolumn{3}{|c|}{$\mathrm{R}^{2}: 4 \mathrm{pm}-7 \mathrm{pm}=51 \%$} \\
\hline \multicolumn{4}{|c|}{ Model fit indices: $\mathrm{CFI}=0.97, \mathrm{NFI}=0.97, \mathrm{GFI}=0.96$, } & \multicolumn{3}{|c|}{$\mathrm{CFI}=0.97, \mathrm{NFI}=0.97, \mathrm{GFI}=0.96$} \\
\hline \multicolumn{4}{|l|}{$A G F I=0.92$, RMSEA $=0.065$} & \multicolumn{3}{|c|}{$\mathrm{AGFI}=0.92, \mathrm{RMSEA}=0.065$} \\
\hline
\end{tabular}

${ }^{\circ} p<0.05,{ }^{* *} p<0.01,{ }^{* * *} p<0.001$, ns Not significant, SE Standard error, CFI Comparative fit index, NFI Norm fit index, GFI Goodness of fit index, AGFI Adjusted goodness of fit index, RMSEA Root mean square error of approximation

peak hours, 6 am to 9 am was not significant $(\beta=0.03$, $\mathrm{t}$-value $=1.67)$ whereas, the movement of private cars $(\beta=0.15$, $\mathrm{t}$-value $=96.00, p<0.001)$ is significant. However, from 9 am to 12 noon, the movement of taxis appears to be slightly more than that of the private cars. On the other hand, from $4 \mathrm{pm}$ to $7 \mathrm{pm}$, private cars move more than the taxis. These findings imply that in Nanjing, most people use their private cars for commuting to work during the morning peak hours and going back home during the evening peak hours from $4 \mathrm{pm}$ to $7 \mathrm{pm}$. However, in between work hours, that is off-peak hours of 9 am to 12 noon most people use public transport or taxis.

The result further indicated that on Thursdays, from 6 am through to 12 noon, the taxis seem to move more than the private cars. However, on the same day, from $4 \mathrm{pm}$ to $7 \mathrm{pm}$, the private cars $(\beta=0.14$, $\mathrm{t}$-value $=124.71$, $p<0.001)$ move more compared to the taxis $(\beta=0.12$, $\mathrm{t}$-value $=7.91, p<0.001)$. Additionally, on Friday mornings, the movement of both private and taxis appears to be in equilibrium, whereas as from $4 \mathrm{pm}$ to $7 \mathrm{pm}$, the taxis move more than the private cars. Finally, on weekends, the movement of taxis seems to be more than the private cars in Nanjing. Nonetheless, from $4 \mathrm{pm}$ to $7 \mathrm{pm}$ the private cars move more than the taxis during weekends.

From the above findings, it is clear that from $4 \mathrm{pm}$ to $7 \mathrm{pm}$ on both weekdays and weekends, there is substantial movement of vehicles thus causing traffic congestion and this could be attributed to the more use of private cars. In addition, from 6 am to 9 am morning peak hours, in the weekdays, the movements of private cars are more than the taxis, except on Thursdays where the taxis move more than the private cars from 6 am through to 12 noon. This also implies that private cars movement during morning peak hours from 6 am to 
9 am is significant and this means that private car usage is still the preferred choice for many travelers due to reasons like comfort, reliability, convenience, privacy [49] and accessibility [50]. Generally speaking, this postulation is in agreement with the hypothesis that private cars contribute to peak hour traffic more than taxis and also conforms with other studies that have proved the preferred use of private cars to public transport [51-53]. In Table 8 , the variance explained in peak and off-peak hours for taxis and private cars are displayed.

\subsection{Road type predicting peak hours for both taxis and private cars}

From Fig. 4, the movement of both taxi and private cars when combined with all the road types (Motorway, primary, secondary and tertiary roads) had a significant relationship with both peak and off-peak hours. Therefore, hypothesis 3 (The choice of road type by cars (taxi and private cars) will significantly influence the movement in peak and off period) is supported. However, on the motorway, the significant coefficient weight is small for both peak and off-peak hour period compared to primary, secondary and tertiary roads. This means that choice of the motorway by vehicles does not influence vehicular movement for both the peak and off-peak hours. However, choice of road types primary, secondary and tertiary have a significant influence on peak hour travels. This postulation is supported by Yazici et al. [42] who exposed in their study that urban road choice is affected by time of the day.

Furthermore, together with the independent variables (Motorway, primary, secondary and tertiary roads), the model explained $62 \%, 80 \%$ and $76 \%$ of the variance in dependent variables, 6 am to 9 am, 9 am to 12 and $4 \mathrm{pm}$ to $7 \mathrm{pm}$ respectively. Based on previous evidence by
Cohen [54] it is obvious that the variance explained by dependent variables are high to support the validity of the current study model using road types in predicting various peak hours.

\subsection{Comparing the choice of road types by private cars and taxis predicting peak hours}

Comparing choice of road types by taxis and private cars, the choice of motorway by private cars was more significant to the various peak hours than the taxis as shown in Table 9, whereas on a tertiary road, the taxis have high significant beta weight than the private cars.

Regarding the choice of primary road, from 6 am to 9 am and $4 \mathrm{pm}$ to $7 \mathrm{pm}$, the private cars had a highly significant coefficient compared to taxis. This indicates that at the morning and evening peak hours, private cars prefer using the primary roads than the other road types. This could also suggest that most private car owners think the congestion on the primary road will be less thus influencing their choice. However, from 9 am to 12 noon, the choice of primary roads by taxis appears to be slightly higher than that of the private cars. This choice could further be substantiated by earlier findings in this study suggesting that there is more movement of taxis during off-peak hours from 9 am to 12 noon than peak periods. The results further show that the choice of the secondary road by private cars highly predicted the morning peak hour 6 am to 9 am, off-peak 9 am to 12 noon and evening peak $4 \mathrm{pm}$ to $7 \mathrm{pm}$, than the taxis, suggesting that in Nanjing, the private cars may frequently choose secondary roads compared to taxis. This further suggests that secondary roads are likely to be congested during these peak periods. The choice of secondary roads by private cars could be because of the

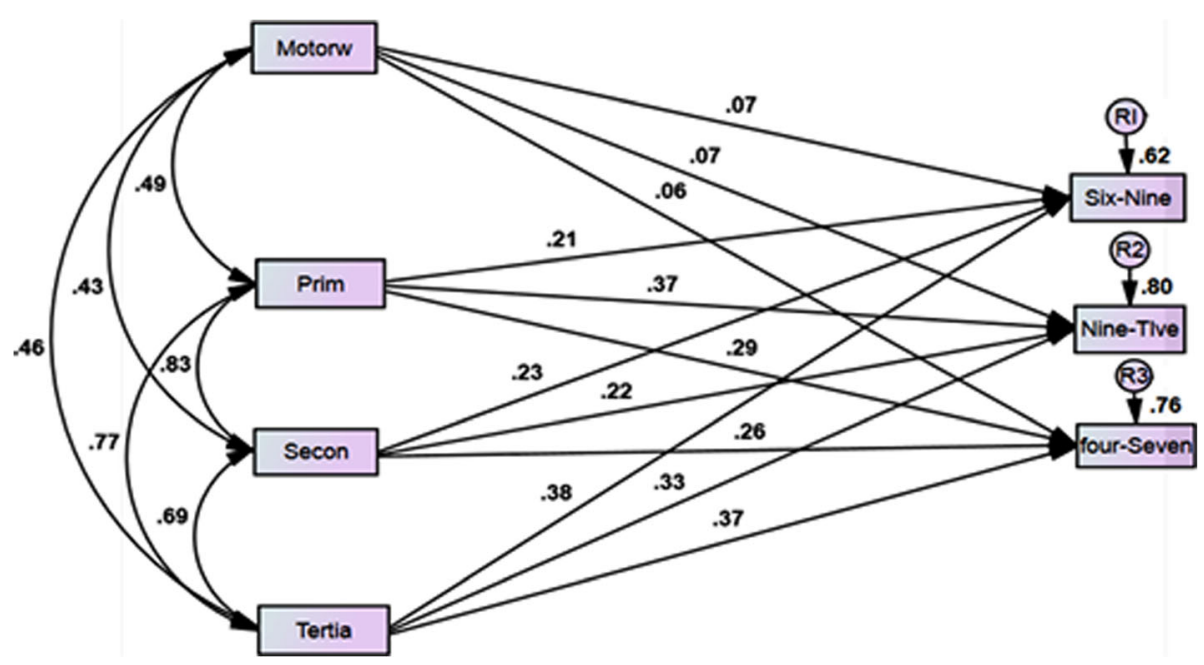

Fig. 4 The relationship between the various road types and peak and off-peak hours (private cars and taxi combined) 
Table 9 Structural Model: Comparing road choice of private car and taxi predicting peak hours

\begin{tabular}{|c|c|c|c|c|c|c|}
\hline \multirow[t]{2}{*}{ Paths } & \multicolumn{3}{|c|}{ Private cars- Default Model $N=819,965$} & \multicolumn{3}{|c|}{ Taxi - Defaults Model $N=10,228$} \\
\hline & Estimate & SE & Critical Ratio & Estimate & SE & Critical Ratio \\
\hline Motorway $\rightarrow 6$ am-9 am & $0.05^{* * *}$ & 0.004 & 56.75 & $0.01^{\mathrm{ns}}$ & 0.060 & 0.70 \\
\hline Motorway $\rightarrow 9$ am-12 noon & $0.07^{* * *}$ & 0.003 & 81.18 & $0.04^{* * *}$ & 0.052 & 6.41 \\
\hline Motorway $\rightarrow 4$ pm-7 pm & $0.04^{* * *}$ & 0.003 & 53.18 & $-0.07^{* * *}$ & 0.051 & -10.08 \\
\hline Primary $\rightarrow 6$ am -9 am & $0.23^{* * *}$ & 0.001 & 185.37 & $0.15^{* * *}$ & 0.005 & 16.43 \\
\hline Primary $\rightarrow 9$ am-12 noon & $0.27^{* * *}$ & 0.001 & 236.78 & $0.31^{* * *}$ & 0.005 & 36.35 \\
\hline Primary $\rightarrow 4 \mathrm{pm}-7 \mathrm{pm}$ & $0.29^{* * *}$ & 0.001 & 311.79 & $0.18^{* * *}$ & 0.005 & 19.71 \\
\hline Secondary $\rightarrow 6$ am-9 am & $0.23^{* * *}$ & 0.001 & 205.68 & $0.25^{* * *}$ & 0.004 & 29.41 \\
\hline Secondary $\rightarrow 9$ am-12 noon & $0.24^{* * *}$ & 0.001 & 235.85 & $0.20^{* * *}$ & 0.004 & 24.68 \\
\hline Secondary $\rightarrow 4$ pm-7 pm & $0.28^{* * *}$ & 0.001 & 326.02 & $0.27^{* * *}$ & 0.004 & 32.56 \\
\hline Tertiary $\rightarrow 6$ am-9 am & $0.31^{* * *}$ & 0.001 & 258.92 & $0.49^{* * *}$ & 0.003 & 62.85 \\
\hline Tertiary $\rightarrow 9$ am-12 noon & $0.32^{* * *}$ & 0.001 & 290.37 & $0.43^{* * *}$ & 0.002 & 59.42 \\
\hline Tertiary $\rightarrow 4 \mathrm{pm}-7 \mathrm{pm}$ & $0.36^{* * *}$ & 0.001 & 392.09 & $0.50^{* * *}$ & 0.002 & 66.29 \\
\hline \multicolumn{4}{|l|}{$R^{2}: 6 a m-9 a m=48 \%$} & \multicolumn{3}{|c|}{$R^{2}: 6 a m-9 a m=50 \%$} \\
\hline \multicolumn{4}{|l|}{$R^{2}: 9$ am-12 noon $=56 \%$} & \multicolumn{3}{|c|}{$\mathrm{R}^{2}: 9 \mathrm{am}-12$ noon $=57 \%$} \\
\hline \multicolumn{4}{|l|}{$R^{2}: 4 p m-7 p m=69 \%$} & \multicolumn{3}{|c|}{$\mathrm{R}^{2}: 4 \mathrm{pm}-7 \mathrm{pm}=53 \%$} \\
\hline \multicolumn{4}{|c|}{ Model fit indices: $\mathrm{CFI}=0.99, \mathrm{NFI}=0.99, \mathrm{GFI}=0.98$} & \multicolumn{3}{|c|}{$\mathrm{CFI}=0.99, \mathrm{NFI}=0.99, \mathrm{GFI}=0.98}$, \\
\hline \multicolumn{4}{|l|}{$\mathrm{AGFI}=0.95, \mathrm{RMSEA}=0.055$} & \multicolumn{3}{|c|}{$\mathrm{AGFI}=0.95, \mathrm{RMSEA}=0.055$} \\
\hline
\end{tabular}

${ }^{* * *} p<0.001$, ns Not significant, SE Standard error, CFI Comparative fit index, NFI Normed fit index, GFI Goodness of fit index, AGFI Adjusted goodness of fit index, RMSEA Root mean square error of approximation

large population in the study area or prior knowledge of all alternative secondary roads.

\section{Conclusions and future work}

The increase of capability of road infrastructure to contain and ease traffic can only be done to an extent as the infrastructure is limited. The onus is therefore on traffic engineers and planners to find intelligent ways to improve and ease congestion. Peak period traffic contributes most to road traffic congestion. The erratic nature of congestion during peak hours makes this study a topical issue for consideration and has motivated researchers to use different methods in finding mitigating measures for congestion. For instance, in Europe researchers have used Remote Traffic Microwave Sensor Data (RTMS), Floating Car Data (FCD) System Anuar et al. [17], De Fabritiis et al. [15], and neural networks Berk Celikoglu [18],Celikoglu [14],De Fabritiis et al. [15], to address traffic flow issues. Others used data collected from FCD and algorithm to identify traffic congestion patterns along urban roads [16]. These studies identified concentrated on morning peak and on urban roads. This paper proposed the need for modeling peak period vehicular movements using the weekday and weekend travel pattern as well as road type choice variability from Radio Frequency Identification (RFID).
Using vehicle movement data from RFID for Nanjing for the month of May 2014, the study employed SEM approach to investigate the effects of weekday and weekend vehicle movements, road type choice and type of car (private cars and taxis) on peak and off-peak period movement. The model results postulated that weekday, weekend, road choice type and car type (taxis and private cars) influence peak and off-peak period traffic in different ways.

The paper shows the prospects and suitability of the choice of variables of weekdays, weekends, road type choice and car type in predicting peak period vehicular movements.

The main findings and significance of this study are as follows:

- The SEM confirms the dominance of weekday travel variable in predicting peak period traffic. There is an evidence of more vehicular movement during weekday peak periods 6 am to 9 am and 4 pm to $7 \mathrm{pm}$ with the morning peak showing similar patterns than evening peak periods. The weight of the significance of weekends predicting peak period vehicular movement was weak, suggesting less possibility of traffic congestion during peak period.

- Private cars predicted peak period vehicular movement more than taxis, especially during 
weekdays. Off-peak period vehicular movements and weekend are more significant with taxis.

- Primary, secondary and tertiary roads are significant in predicting peak period vehicular movement. Motorway, on the other hand, was not so significant in predicting peak period movements when both taxis and private cars were considered together but had a higher significance for private cars in predicting peak period movement when the types of cars were considered separately. Taxis had high usage of tertiary roads during peak hours whereas private cars used primary and secondary roads more during peak hours. The preference for certain road types during peak and off-peak hours is information for traffic engineers to investigate and make choice of all road types attractive to prevent traffic congestion.

- The study has proved the viability of this modeling method to aid policy measures to reduce peak period congestion with informed knowledge from vehicular movement on weekdays, weekends, road type choice and car type.

The study, therefore, contributes to transportation improvement processes to inform road traffic authorities on adequate measures to adjust hours and approaches to operations [55]. The revealing of preference use of car [56] particularly of private cars [53] in this study which is likely to lead to congestion can also be mitigated by offering incentives for the use of public transport and disincentives for use of private cars. This study will, therefore, contribute sufficient proof to car owners, transportation planning engineers, and politicians on the possible negative impact of the use of private cars on traffic congestion.

Future considerations for this study include a more disaggregated approach where each of the days in the month could be investigated to find similar patterns in the days instead of grouping them under weekdays and weekends. It is also suggested that a traffic flow model is developed for each of the streets captured by the RFID reader to determine the number of vehicles that cause peak hour congestion on each street and what critical times they occur. Further investigation can also be made to determine the reason for the choice of the road types based on revealed preference method of RFID and supported by stated preference methods using questionnaires.

\section{Acknowledgments}

The authors thank all anonymous reviewers for their comments on this study. This research is supported by Chinese Scholarship Council (CSC) [grant number 2015GXZ067].

\section{Authors' contributions}

TDW and SZ formulated the research topic. TDW, CA and SZ researched on the methods to use. SZ facilitated the acquisition of the data and materials.
TDW and CA perfomed the data processing and analysis. TDW, SZ and CA presented the results, wrote the conclusion and suggestions for future works. All authors read and approved the final manuscript.

Competing interests

The authors declare that they have no competing interests.

\section{Publisher's Note}

Springer Nature remains neutral with regard to jurisdictional claims in published maps and institutional affiliations.

\section{Author details}

${ }^{1}$ School of Transportation, Department of Traffic Engineering, Wuhan University of Technology, 1040 Heping Avenue, Wuhan 430063, Hubei, China. ${ }^{2}$ Department of Civil Engineering, Accra Technical University, P.O. Box 561, Accra, Ghana. ${ }^{3}$ Ho Technical University, P.O. Box HP 217, Ho, Volta Region, Ghana.

Received: 8 January 2018 Accepted: 22 August 2018

Published online: 03 September 2018

References

1. Communities CotE (2008) Proposal for a directive of the European Parliament and of the council, laying down the framework for the deployment of intelligent transport systems in the field of road transport and for interfaces with other transport modes (online).

2. Kuppam AR, Pendyala RM (2001) A structural equations analysis of commuters' activity and travel patterns. Transportation 28(1):33-54. https://doi.org/10.1023/A:1005253813277.

3. Zuidgeest MHP (2005) Sustainable urban transport development: a dynamic optimisation approach. University of Twente, The Netherlands

4. Flamini M, Nigro M, Pacciarelli D (2011) Assessing the value of information for retail distribution of perishable goods. Eur Transp Res Rev 3(2):103-112. https://doi.org/10.1007/s12544-011-0051-8

5. Communities CotE (2008) Action plan for the deployment of intelligent transport systems in Europe.

6. Seedam A, Satiennam T, Radpukdee T, Satiennam W, Ratanavaraha V (2017) Motorcycle on-road driving parameters influencing fuel consumption and emissions on congested signalized urban corridor. J Adv Transp 2017. https://doi.org/10.1155/2017/5859789

7. Yan Y, Zhang S, Tang J, Wang X (2017) Understanding characteristics in multivariate traffic flow time series from complex network structure. Physica A: Statistical Mechanics and its Applications 477:149-160. https://doi.org/10. 1016/j.physa.2017.02.040

8. Bates J, Polak J, Jones P, Cook A (2001) The valuation of reliability for personal travel. Transportation Research Part E: Logistics and Transportation Review 37(2):191-229. https://doi.org/10.1016/S1366-5545(00)00011-9

9. Loudon WR, Ruiter ER, Schlappi ML (1988) Predicting Peak-Spreading Under Congested Conditions, vol 1203

10. Downs A (1962) The law of peak-hour expressway congestion. Traffic Quarterly 16(3)

11. Li M, Song G, Cheng Y, Yu L (2015) Identification of prior factors influencing the mode choice of short distance travel. Discret Dyn Nat Soc 2015. https:// doi.org/10.1155/2015/795176

12. Ben-Akiva M, De Palma A, Kanaroglou P (1986) Dynamic model of peak period traffic congestion with elastic arrival rates. Transp Sci 20(3):164-181

13. Lyons L, Lozano A, Granados F, Guzmán A (2017) Impacts of time restriction on heavy truck corridors: the case study of Mexico City. Transp Res A Policy Pract 102:119-129. https://doi.org/10.1016/j.tra.2017.03.012

14. Celikoglu HB (2014) Dynamic classification of traffic flow patterns simulated by a switching multimode discrete cell transmission model. IEEE Trans Intell Transp Syst 15(6):2539-2550. https://doi.org/10.1109/TITS.2014.2317850

15. De Fabritiis C, Ragona R, Valenti G Traffic estimation and prediction based on real time floating car data. In: Intelligent Transportation Systems, 2008. ITSC 2008. 11th International IEEE Conference, IEEE on October 12-15, 2008. Beijing. pp 197-203

16. Altintasi O, Tuydes-Yaman H, Tuncay K (2017) Detection of urban traffic patterns from Floating Car Data (FCD). Transportation Research Procedia 22:382-391

17. Anuar K, Habtemichael F, Cetin M (2015) Estimating Traffic Flow Rate on Freeways from Probe Vehicle Data and Fundamental Diagram. In: 2015 IEEE 18th International Conference on Intelligent Transportation Systems, 15-18 Sept. 2015, pp 2921-2926. https://doi.org/10.1109/ITSC.2015.468 
18. Berk Celikoglu H (2013) An Approach to Dynamic Classification of Traffic Flow Patterns, vol 28. https://doi.org/10.1111/j.1467-8667.2012.00792.x

19. Cheng SD, Zhang GH, Liu MJ, Wu KH (2013) Data Availability for Measuring and Reporting Transport related Greenhouse Gas Emissions in Chinese Cities.

20. SAP (2015) Smart cities - how SAP helps clear traffic jams. https://news.sap. com/2015/04/sap-helps-clear-traffic-jams. Accessed 24 Oct 2017

21. Manoj M, Verma A (2017) A structural equation model based analysis of non-workers' activity-travel behaviour from a city of a developing country. Transportation 44(2):241-269. https://doi.org/10.1007/s11116-015-9636-8

22. Bollen K (1989) Structural equations with latent variables. John Wiley, New York

23. Van Acker V, Witlox F (2010) Car ownership as a mediating variable in car travel behaviour research using a structural equation modelling approach to identify its dual relationship. J Transp Geogr 18(1):65-74

24. Kline RB (2015) Principles and practice of structural equation modeling. Guilford publications, New York

25. Golob TF (2003) Structural equation modeling for travel behavior research. Transp Res B Methodol 37(1):1-25. https:/doi.org/10.1016/S0191-2615(01)00046-7

26. Beran TN, Violato C (2010) Structural equation modeling in medical research: a primer. BMC research notes 3(1):267. https://doi.org/10.1186/ 1756-0500-3-267 http://www.ncbi.nlm.nih.gov/pubmed/20969789

27. MacCallum RC, Austin JT (2000) Applications of structural equation modeling in psychological research. Annu Rev Psychol 51(1):201-226. https://doi.org/10.1146/annurev.psych.51.1.201 http://www.ncbi.nlm.nih.gov/ pubmed/10751970

28. Singh V, Sharma SK (2016) Analyzing the moderating effects of respondent type and experience on the fuel efficiency improvement in air transport using structural equation modeling. Eur Transp Res Rev 8(2):12. https://doi. org/10.1007/s12544-016-0199-3

29. Kurle S, Behara KN, Prasad JR, Arkatkar S, Sarkar AK (2016) Study of lane utilization on Delhi-Gurgaon expressway. Transportation Research Procedia 17:674-684. https://doi.org/10.1016/j.trpro.2016.11.122

30. Qin H, Guan H, Zhang G (2012) Analysis of the travel intent for park and ride based on perception. Discret Dyn Nat Soc. https://doi.org/10.1155/ 2012/516197

31. Jin Kim H, Hoon Kim D, Chung J-H (2004) Weekend activity and travel behavior in a developing country: empirical study using multilevel structural equation models. Transportation Research Record: Journal of the Transportation Research Board 1894:99-108

32. Eboli L, Mazzulla G (2012) Structural equation modelling for analysing passengers' perceptions about railway services. Procedia Soc Behav Sci 54: 96-106. https://doi.org/10.1016/j.sbspro.2012.09.729

33. Smith OB (2013) Peak of the day or the daily grind: commuting and subjective well-being. Portland State University, Oregon

34. Laube $P$ (2015) The low hanging fruit is gone: achievements and challenges of computational movement analysis. SIGSPATIAL Special 7(1):3-10. https:// doi.org/10.1145/2782759.2782762

35. Van Wee B, Geurs K, Chorus C (2013) Information, communication, travel behavior and accessibility.

36. Yu R, Wang X, Yang K, Abdel-Aty M (2016) Crash risk analysis for shanghai urban expressways: a Bayesian semi-parametric modeling approach. Accid Anal Prev 95(Pt B):495-502. https://doi.org/10.1016/j.aap.2015.11.029 http:// www.ncbi.n/m.nih.gov/pubmed/26847949

37. Loudon WR, Ruiter ER, Schlappi ML (1988) Predicting peak-spreading under congested conditions. Demand forecasting and trip generation-route choice dynamics. Transportation Research Board, Washington, D.C.

38. Chen XH, Shan XN, Ye JH, Yi FB, Wang YF (2017) Evaluating the effects of traffic congestion and passenger load on feeder bus fuel and emissions compared with passenger Car. In: Ulengin F, Li K, Boltze M (eds) World conference on transport research - Wctr 2016, vol 25. Transportation Research Procedia. Elsevier Science Bv, Amsterdam, pp 616-626. https://doi. org/10.1016/j.trpro.2017.05.446

39. Chiou YC, Fu C (2017) Responses of drivers and motorcyclists to congestion charge. In: Ulengin F, Li K, Boltze M (eds) World conference on transport research - Wctr 2016, vol 25. Transportation Research Procedia. Elsevier Science Bv, Amsterdam, pp 2961-2973. https://doi.org/10.1016/j.trpro. 2017.05.197

40. Holguin-Veras J, Wang QA, Xu N, Ozbay K (2011) The impacts of time of day pricing on car user behavior: findings from the port Authority of New York and New Jersey's initiative. Transportation 38(3):427-443. https://doi.org/10. 1007/s11116-010-9307-8
41. Ben-Elia E, Ettema D (2011) Rewarding rush-hour avoidance: a study of commuters' travel behavior. Transp Res Pt A-Policy Pract 45(7):567-582. https://doi.org/10.1016/j.tra.2011.03.003

42. Yazici M, Kamga C, Ozbay K (2014) Highway versus urban roads: analysis of travel time and variability patterns based on facility type. Transportation Research Record: Journal of the Transportation Research Board 2442:53-61. https://doi.org/10.3141/2442-07

43. Tarko A, Perez-Cartagena R (2005) Variability of peak hour factor at intersections. Transportation Research Record: Journal of the Transportation Research Board 1920:125-130

44. Anderson JC, Gerbing DW (1988) Structural equation modeling in practice: a review and recommended two-step approach. Psychol Bull 103(3):411

45. Atombo C, Wu C, Zhang H, Wemegah TD (2017) Perceived enjoyment, concentration, intention, and speed violation behavior: using flow theory and theory of planned behavior. Traffic Inj Prev 18(7):694-702. https://doi. org/10.1080/15389588.2017.1307969

46. Hair J (2010) Multivariate data analysis Pearson College Division.

47. Viti F, Tampère C, Frederix R, Castaigne M, Cornelis E, Walle F (2010) Analyzing weekly activity-travel behavior from behavioral survey and traffic data. In: World conference on transport research

48. Li R, Rose G, Sarvi M (2006) Using automatic vehicle identification data to gain insight into travel time variability and its causes. Transportation Research Record: Journal of the Transportation Research Board 1945:24-32

49. Downs A (2004) Traffic: Why It's Getting Worse, What Government Can Do. Brookings Institution, Washington, DC

50. Yatskiv I, Budilovich E (2017) Evaluating Riga transport system accessibility. In: Kabashkin I, Yatskiv I, Prentkovskis O (eds) Proceedings of the 16th international scientific conference reliability and statistics in transportation and communication, Procedia Engineering, vol 178. Elsevier Science Bv, Amsterdam, pp 480-490. https://doi.org/10.1016/j.proeng.2017.01.091

51. Gärling T, Schuitema G (2007) Travel demand management targeting reduced private car use: effectiveness, public acceptability and political feasibility. J Soc Issues 63(1):139-153

52. Jakobsson C, Fujii S, Gärling T (2002) Effects of economic disincentives on private car use. Transportation 29(4):349-370. https://doi.org/10.1023/A: 1016334411457

53. Steg L (2005) Car use: lust and must. Instrumental, symbolic and affective motives for car use. Transp Res A Policy Pract 39(2):147-162. https://doi.org/ 10.1016/.j.tra.2004.07.001

54. Cohen J (1988) Statistical power analysis for the behavioral sciences, Lawrence Erlbaum Associates, New York. https://doi.org/10.4324/9780203771587

55. Systematics C (2005) Traffic congestion and reliability: trends and advanced strategies for congestion mitigation. Final report, Texas transportation institute. https://ops.fhwa.dot.gov/congestion_report_04/index.htm

56. Steg L, Geurs K, Ras M (2001) The effects of motivational factors on car use: a multidisciplinary modelling approach. Transp Res A Policy Pract 35(9): 789-806

\section{Submit your manuscript to a SpringerOpen ${ }^{\circ}$ journal and benefit from:}

- Convenient online submission

- Rigorous peer review

- Open access: articles freely available online

- High visibility within the field

- Retaining the copyright to your article

Submit your next manuscript at $>$ springeropen.com 